\title{
QUANTUM WELL THERMOELECTRICS FOR CONVERTING WASTE HEAT TO ELECTRICITY
}

\author{
QUARTERLY TECHNICAL PROGRESS REPORT
}

REPORTING PERIOD 10-01-2004 THROUGH 12-31-2004

Submitted By

Hi-Z Technology, Inc.

7606 Miramar Road, Suite 7400

San Diego, CA 92126

\section{Prepared By}

Dr. Saeid Ghamaty, P.I

Mr. Sal Marchetti, Project Controls

Phone (858) 695-6660

FAX (858) 695-8870

Issued March 3, 2005 


\section{DISCLAIMER}

"This report was prepared as an account of work sponsored by an agency of the United States Government. Neither the United States Government nor any agency thereof, nor any of their employees, makes any warranty, express or implied, or assumes any legal liability or responsibility for the accuracy, completeness, or usefulness of any information, apparatus, product, or process disclosed, or represents that its use would not infringe privately owned rights. Reference herein to any specific commercial product, process, or service by trade name, trademark, manufacture, or otherwise does not necessarily constitute or imply its endorsement, recommendation, or favoring by the United States Government or any agency thereof. The views and opinions of authors expressed herein do not necessarily state or reflect those of the United States Government or any agency thereof." 


\begin{abstract}
New thermoelectric materials using Quantum Well (QW) technology are expected to increase the energy conversion efficiency to more than $25 \%$ from the present $5 \%$, which will allow for the low cost conversion of waste heat into electricity.

Hi-Z Technology, Inc. has been developing QW technology over the past six years. It will use Caterpillar, Inc., a leader in the manufacture of large scale industrial equipment, for verification and life testing of the QW films and modules.

Other members of the team are Pacific Northwest National Laboratory, who will sputter large area QW films. The Scope of Work is to develop QW materials from their present proof-of-principle technology status to a pre-production level over a proposed three year period. This work will entail fabricating the QW films through a sputtering process of $50 \mu \mathrm{m}$ thick multi layered films and depositing them on 12 inch diameter, $5 \mu \mathrm{m}$ thick Si substrates.

The goal in this project is to produce a basic 10-20 watt module that can be used to build up any size generator such as: a 5-10 kW Auxiliary Power Unit (APU), a multi kW Waste Heat Recovery Generator (WHRG) for a class 8 truck or as small as a 10-20 watt unit that would fit on a daily used wood fired stove and allow some of the estimated 2-3 billion people on earth, who have no electricity, to recharge batteries (such as a cell phone) or directly power radios, TVs, computers and other low powered devices.
\end{abstract}




\section{TABLE OF CONTENTS}

$1 \quad$ List of Graphics

2 Introduction

3 Executive Summary

4 Progress By Tasks/Experimental/Results and Discussions/Conclusions

$5 \quad$ References 


\section{LIST OF GRAPHICS}

Figure 1. QW Couple for thermal stability test.

Figure 2. Isothermal aging studies of QW B4C/B9C-Si/SiGe Couple.

Figure 3. Thermal aging $\mathrm{Si} / \mathrm{SiGe}$ leg.

Figure 4. Isothermal aging studies of B4C/B9C leg.

Figure 5. Thermal aging of Ag contact.

Figure 6. Thermal aging $\mathrm{Si} / \mathrm{SiGe}$ leg power number.

Figure 7. Isothermal aging studies of B4C/B9C power number.

Figure 8. Life testing of QW Couple.

Figure 9. Isothermal aging studies of QW B4C/B9C-Si/SiGe Couple Mo contact.

Figure 10. Thermal aging of Mo contact.

Figure 11. Thermal aging of Mo contact power number.

Figure 12. PNNL Experimental Results.

Figure 13. NRL results.

Figure 14. ZT time line.

Figure 15. The new sputtering system.

Table 1. Thermoelectric properties of QW couple with Mo contact.

Table 2. TE Properties Comparison.

\section{INTRODUCTION}

$\mathrm{Hi}-\mathrm{Z}$ is making progress on the development of a new type of thermoelectric conversion device called Quantum Wells (QW). Hi-Z has recently measured power and efficiency demonstrating a QW couple conversion efficiency of $14 \%$, using a $11 \mu \mathrm{m}$ QW film deposited on a $5 \mu \mathrm{m}$ thick silicon substrate. The thickness of the films, area of deposition, and the method of joining $\mathrm{N}$ and $\mathrm{P}$ legs is the substance of this research and development effort.

\section{EXECUTIVE SUMMARY}

In this quarter Hi-Z started fabrication of thicker $(>11: \mathrm{m}) \mathrm{QW}$ films and also started development of joining techniques for fabricating the $\mathrm{N}$ and $\mathrm{P}$ legs into a couple. The upper operating temperature limit for these films is unknown and will be determined via the isothermal aging studies that are in progress. Fabrication of the films from the present $11 \mu \mathrm{m}$ with an efficiency $14 \%$ to the 30 $50 \mu \mathrm{m}$ range with a possible efficiency of $\sim 21 \%$, is expected to be difficult since the added layers could induce stresses that will lead to warping or cracking of the films and the Si substrate. The sputtering techniques has been modified to develop these much thicker films. We are reporting on these studies in this report. The properties of the QW films that are being evaluated are Seebeck, thermal conductivity and thermal-to-electricity conversion efficiency. 


\section{PROGRESS BY TASKS/EXPERIMENTAL/RESULTS AND DISCUSSION/ CONCLUSIONS}

\section{Electrical Contacts for QWs}

The requirement for contacts of the $\mathrm{QW} \mathrm{Si} / \mathrm{SiGe}-\mathrm{B}_{4} \mathrm{C} / \mathrm{B}_{9} \mathrm{C}$ are as follow:

- Low electrical resistance contact

- Use known compatible and conductive materials, e.g., metals Mo, W, Au, Ti.

- Control residual oxide at interface, e.g., interstitial sink; $\mathrm{Si} / \mathrm{SiGe}, \mathrm{B} 4 \mathrm{C} / \mathrm{B} 9 \mathrm{C}$, and $\mathrm{Si} / \mathrm{SiC}$

all have tenacious oxide films that need to be penetrated.

- $\quad$ Thermal Stability- Avoid residual stress by expansion match, Avoid contact stress

raisers, e.g., oxides, voids

- $\quad$ Provide ductility to absorb thermal stresses

- $\quad$ Strength - reduce source of stress; increase strength, e.g., SiC for solar cells

$\mathrm{Ni} / \mathrm{WSi} / \mathrm{Ti} / \mathrm{Pt}$ contacts. Auger spectroscopy shows oxygen peak in titanium as fabricated.

This increases contact strength (and lowers electrical resistance)

- $\quad$ Life- Control growth of brittle, stress raising compounds, provide high strength to withstand thermal stresses

Sweet et al of Sandia evaluate $\mathrm{W}$ deposits for connections for SiGe thermoelectric materials. The effect of residual silicon oxide films and life determination were the principal areas of study. Useful insights were provided on several issues relative to QW requirements. The authors assumed a model where the retained oxide films at the W/Si20Ge interface were thin so that conduction by tunneling was an important contributor and where life was determined by growth of $\mathrm{WSi}_{2}$. The $\mathrm{SiO}_{2}$ was assessed to be $10-15 \mathrm{D}$ by Auger spectroscopy. The time to rapid increase in resistance under isothermal holds followed an Arrhenius relationship with the activation energy following that expected for $\mathrm{W} / \mathrm{SiGe}$ formation from the elements.

The thin, uniform oxide film model was disproved by a doubling of resistance as film thickness went from 10 to 15D. A tunneling mechanism required a 35X increase. The improbability of the model was supported by the statement that the assemblage was made by "press bonding". This will lead to mechanical damage resulting on a classical electrical contact such as that described by Ragnar Holm (Electrical Contacts). Further, a film of this thickness is thermodynamically unstable because of the high surface-to-volume relationship; such instability leads to spheroidization to reduce surface energy as discussed by Flynn.

The classical electrical contact consists of disconnected, partially spheroidized particulate oxide with conductive elements in contact in the intervening areas.

The authors show a slow increase in resistivity followed by a much more rapid increase at a critical time that was independent of the thickness of the tungsten in the range 1-3 $\mu \mathrm{m}$. Transition to the rapid increase time followed an Arrhenius relationship related to $\mathrm{WSi}_{2}$ formation. This occurred at a critical thickness of $\mathrm{WSi}_{2}$ equal to approximately $200 \mathrm{D}$ with local unbonding and complete loss of adhesion.

The authors show evidence of cracking once the contact resistance had risen to high values. 
Review of the system indicates that tungsten $\left(\mathrm{COE} 4.3 \times 10^{-6} \mathrm{C}^{-1}\right)$ is a close match to Si-20Ge (estimated $\left.3.2 \times 10^{-6} \mathrm{C}^{-1}\right)$ whereas molybdenum is not as close a match $\left(5 \times 10^{-6} \mathrm{C}^{-1}\right)$. On the other hand, $\mathrm{WSi}_{2}$ was the only phase found by the authors (COE is $7.9 \times 10^{-6}$ and the closely related $\mathrm{MoSi}_{2}$ is $8.25 \times 10^{-6} \mathrm{C}^{-1}$ ). In contrast, molybdenum forms several intermediate silicides including the closely matched $\mathrm{Mo}_{3} \mathrm{Si}\left(\mathrm{COE} 4.3 \times 10^{-6} \mathrm{C}^{-1}\right)$ so that disilicide formation will lead to high stresses in the W/Si20Ge system.

It can be concluded that

1. Si-20Ge has a better expansion match for W- or Mo-based connector systems than Si.

2. The disilicide $\mathrm{WSi}_{2}$ has a major mismatch in COE and will cause cracking and loss of contact.

3. It appears that a minimum thickness of $\mathrm{WSi}_{2}$ is necessary to cause fractures in the $\mathrm{W} / \mathrm{Si}$-20Ge connector system. The lower expansion of $\mathrm{Si}\left(2.5 \times 10^{-6} \mathrm{C}^{-1}\right)$ would be expected to result in fracture at a lower critical thickness of $\mathrm{WSi}_{2}$.

4. The absence of intermediate (COE) silicides with tungsten observed by Sweet et al is a limiting factor in the life of these contacts.

5. $\mathrm{Si}-30 \mathrm{Ge}$ is probaly bether than $\mathrm{Si}-20 \mathrm{Ge}$ since more $\mathrm{Ge}$ will slow down $\mathrm{WSi}_{2}$ formation

The authors do not discuss the mechanism of formation of $\mathrm{WSi}_{2}$ if a continuous $\mathrm{SiO}_{2}$ is present. In the more likely absence of such a continuous film, then $\mathrm{WSi}_{2}$ will grow at all sites where $\mathrm{W}$-to$\mathrm{Si}(20 \mathrm{Ge})$ contact occurs. Growth will be dependent on rejection of Ge (as no Ge is present in either silicide or oxide) so that diffusion away of the Ge may be a rate controlling step. This point, also, is not discussed by Sweet et al.

An interstitial sink (see Metcalfe and Dunning) for oxygen is frequently used in contacts (e.g.,Pt/Ti/WSi/Ni used for $\mathrm{SiC}$-base solar cells). Removal of oxides from the interface will remove oxide stress concentrators that both weaken the connection, and increase the resistance. On the other hand, silicide formation can occur over the entire area. Nevertheless, there would seem to be a net advantage over a connection without an interstitial sink. We are preparing metal sprayed samples for contact with Mo which will be evaluated shortly.

\section{Thermal Stability of $\mathrm{Si} / \mathrm{SiGe}-\mathrm{B}_{4} \mathrm{C} / \mathrm{B}_{9} \mathrm{C}$ Couple}

Figure 1 shows a new $\mathrm{QW}$ couple with $\mathrm{B}_{4} \mathrm{C} / \mathrm{B}_{9} \mathrm{C}$ and $\mathrm{Si} / \mathrm{SiGe}$ insulated with Alumina. Four couples were fabricated for a new thermal stability test for temperatures 300, 400, 500 and 600/C. A combination of sputter Au and Ag epoxy was used to make contact for the three couple and Mo metal was used for the fourth couple. Laser assisted sputtering was used to fabricate the Mo metal contact. As was mentioned on the previous reports, the joints are being made by silver epoxy and while this may be acceptable for low temperature service, long term low resistance stable bonds are needed for high temperature generation. Critical to this need is that each $100 \mathrm{D}$ thick layer needs to be metallurgically contacted or "wetted" to obtain the lowest possible contact resistance.

Figures 2 through 7 show the latest isothermal data for the couples, the total aging time has been increased to 400 hours. The resistance ratio shown in the Figure 2 includes both the resistance of the both $\mathrm{QW} \mathrm{Si} / \mathrm{SiGe}$ plus $\mathrm{B}_{4} \mathrm{C} / \mathrm{B}_{9} \mathrm{C}$ as well as the $\mathrm{Ag}$ conductive epoxy used to make the low 
resistance contact. As shown in these Figures 2-7 the data still supports that over $90 \%$ thermal aging effects are from contacts. Both $\mathrm{Si} / \mathrm{SiGe}$ and $\mathrm{B}_{4} \mathrm{C} / \mathrm{B}_{9} \mathrm{C}$ legs show very little change over the time even at 600/C (Figures 3, 4, 6 and 7). Developing low resistance electrical contacts to the $\mathrm{QW}$ materials of $\mathrm{Si} / \mathrm{SiGe}$ to $\mathrm{B}_{4} \mathrm{C} / \mathrm{B}_{9} \mathrm{C}$ at 400 , 500 , and $600^{\circ} \mathrm{C}$ are underway indicating little or no change in total electrical properties with time.

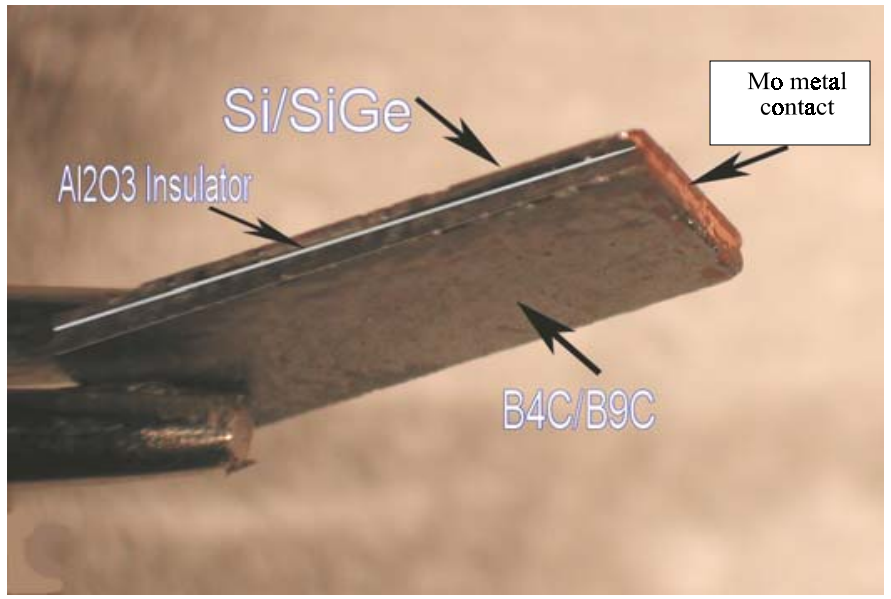

Figure 1. QW Si/SiGe- $\mathrm{B}_{4} \mathrm{C} / \mathrm{B}_{9} \mathrm{C}$ couple for thermal stability test. The Mo was deposited by an improved sputtering process. This is the first couple where an $\mathrm{Al}_{2} \mathrm{O}_{3}$ insulator was used. Other oxides, such as stabilized $\mathrm{ZrO}_{2}$, with much lower thermal conductivities will be incorporated in future couples.

\section{Thermal aging QW couple resistance ratio}

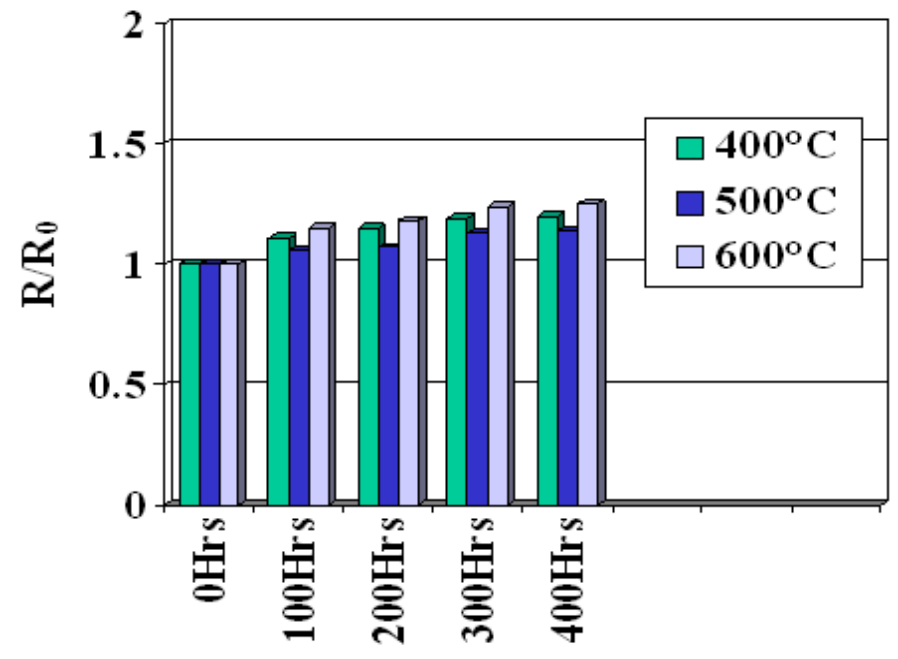

Figure 2. Isothermal aging studies of $\mathrm{Si} / \mathrm{SiGe}-\mathrm{B}_{4} \mathrm{C} / \mathrm{B}_{9} \mathrm{C}$ couple.

$\mathrm{Y}$-axis is the resistivity ratio at various aging time. The resistance ratio includes both the resistance of the QW Si/SiGe plus $\mathrm{B}_{4} \mathrm{C} / \mathrm{B}_{9} \mathrm{C}$ samples as well as the $\mathrm{Ag}$ conductive epoxy used to make the low resistance contact. Individual aging of the contact and the QW films are shown in the following figures. 


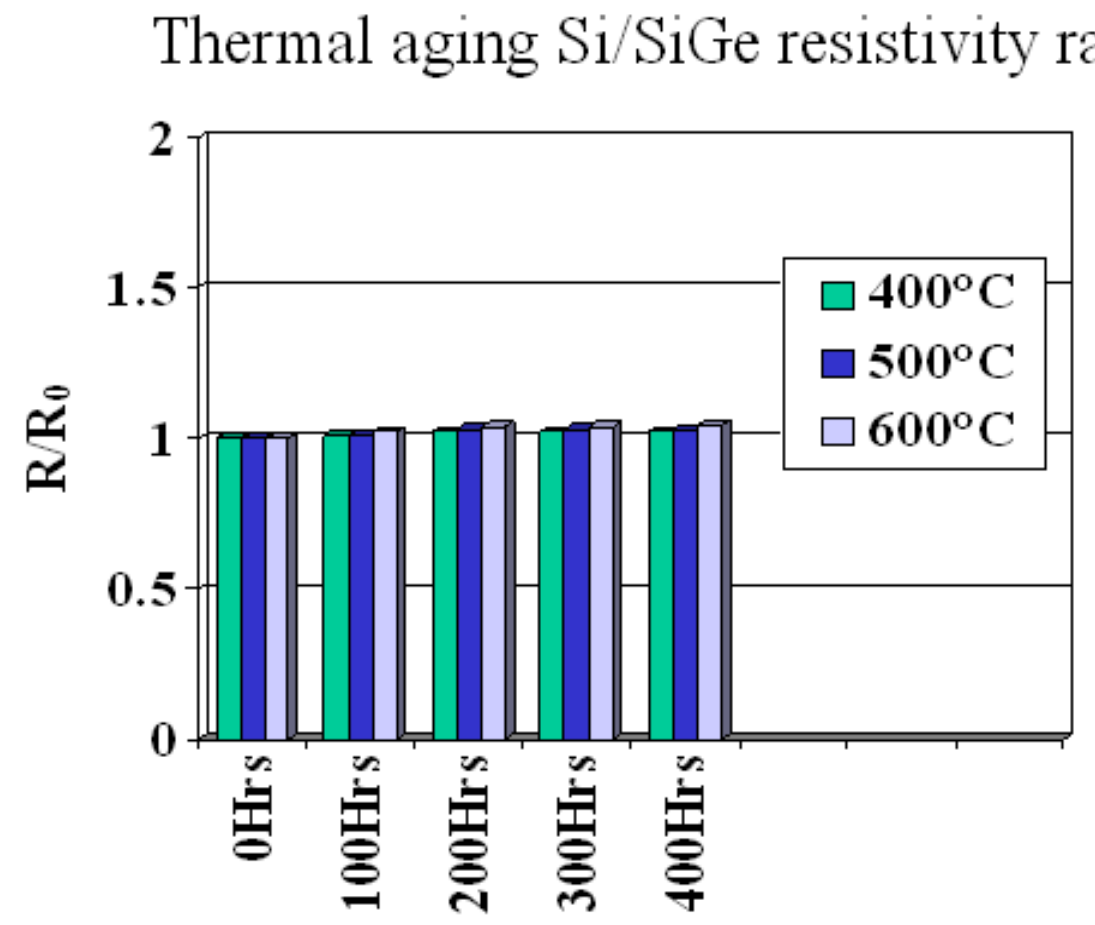

Figure 3. Thermal aging Si/SiGe leg.

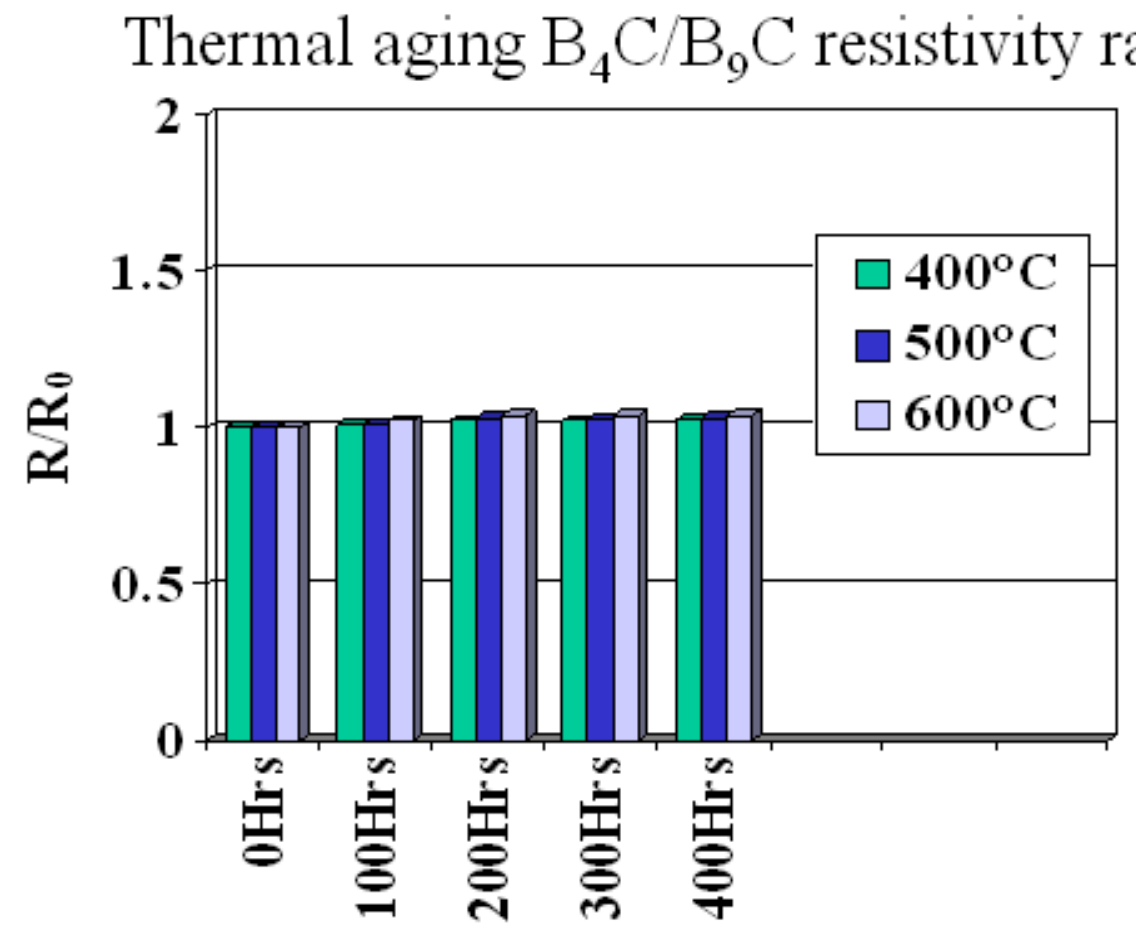

Figure 4. Thermal aging $B_{4} C / B_{9} C$ leg. 


\section{Thermal aging contact resistance ratio}

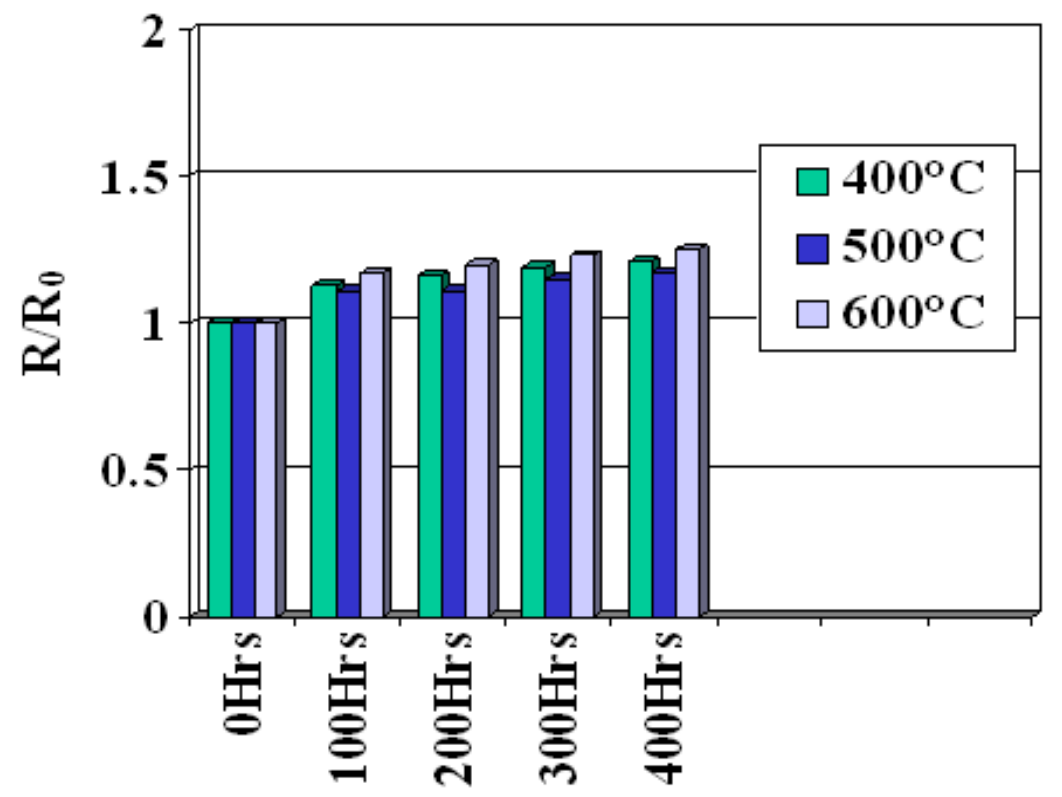

Figure 5. Thermal aging of sputtered Au and Ag epoxy.

\section{Thermal aging $\mathrm{Si} / \mathrm{SiGe}$ power\# ratio}

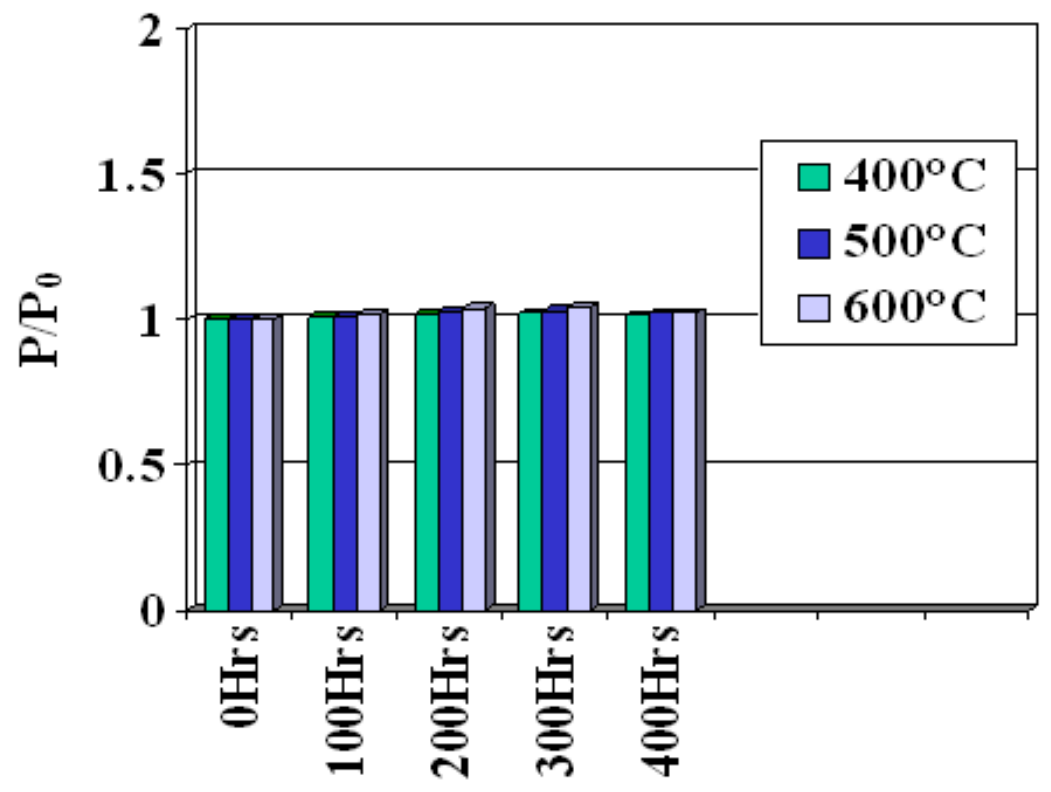

Figure 6. Thermal aging of Si/SiGe leg power number $="$ 2/D 


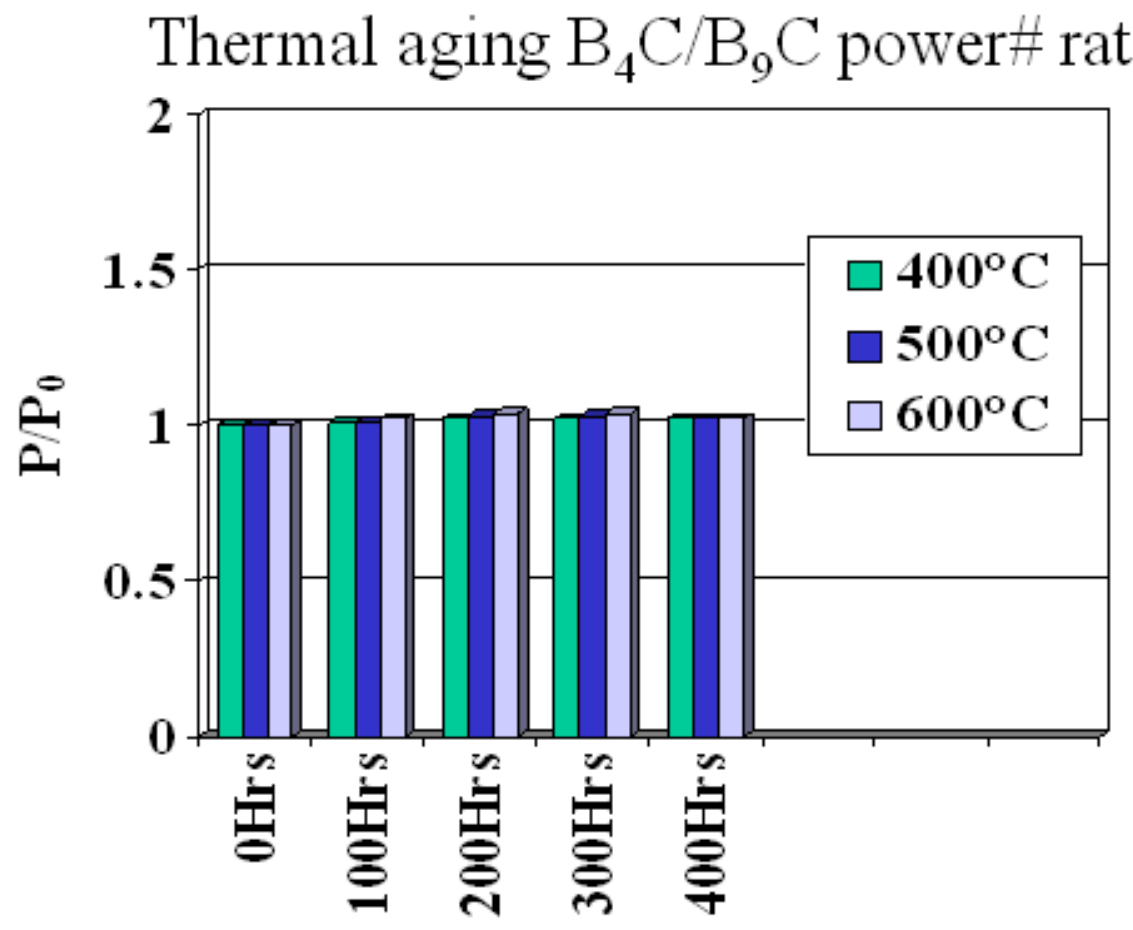

Figure 7. Thermal aging of $B_{4} C / B_{9} C$ leg power number $=" 2 / D$.

\section{Mo Contacts}

Figure 1 shows a recent $\mathrm{QW}$ couple with $\mathrm{B}_{4} \mathrm{C} / \mathrm{B}_{9} \mathrm{C}$ and $\mathrm{Si} / \mathrm{SiGe}$. This couple was fabricated for a new round of thermal stability testing for high temperatures. An improved sputtering process was successfully developed to deposit the Mo metal contacts that exhibit a negligible contact resistance with both $\mathrm{N}$ and $\mathrm{P}$ material. The potential problem with contact resistance was previously highlighted but this newly developed sputtering process appears to demonstrate that this problem can be overcome and high efficiency modules can be fabricated.

Initial thermal stability testing of the Mo contacted couple at annealing of the $\mathrm{B}_{4} \mathrm{C} / \mathrm{B}_{9} \mathrm{C}$ which typically improves in $\mathrm{T}_{\mathrm{H}}=300^{\circ} \mathrm{C}$ and $\mathrm{T}_{\mathrm{C}}=50^{\circ} \mathrm{C}$ for 700 hours Seebeck coefficient in the first few hundred hours. showed very stable performance as

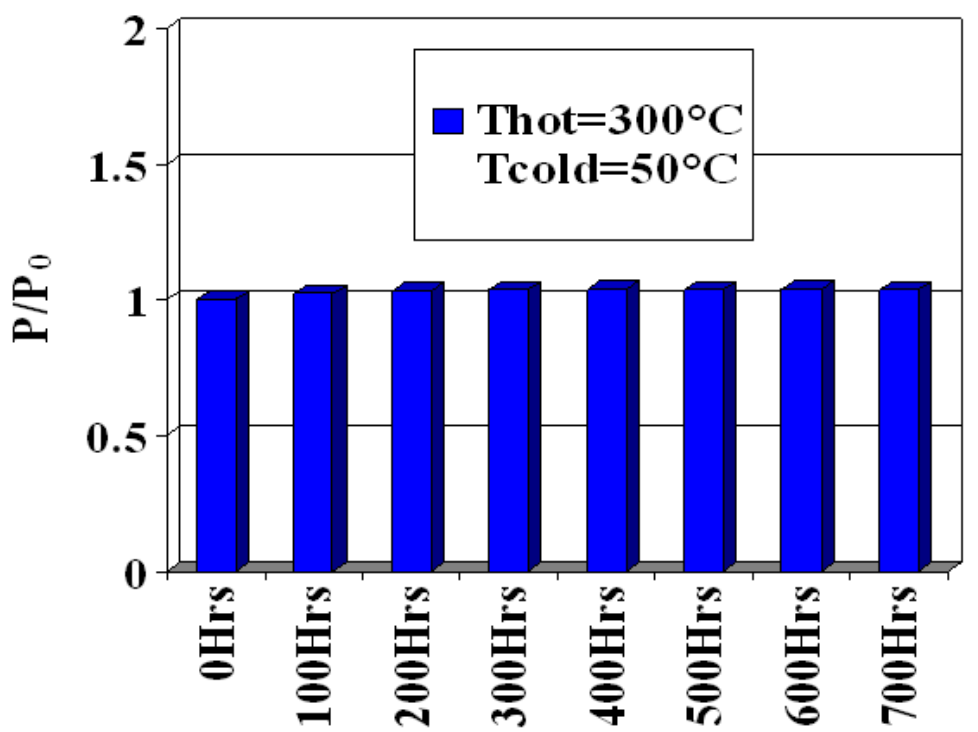

Figure 8. Life testing of QW couple with Mo contacts. The power is obtained by measuring " $2 / D$, where " is the Seebeck cofficient, and Dis the electrical resistivity. 
shown by the very negligible change in power with time. Figure 7 shows these results which appear very promising. Also, isothermal testing of the individual $\mathrm{B}_{4} \mathrm{C} / \mathrm{B}_{9} \mathrm{C}$ and $\mathrm{Si} / \mathrm{SiGe}$ films up to $600^{\circ} \mathrm{C}$ for 800 hours has shown stable thermoelectric properties, as shown in Figures 7, and 9-11. We will continue the thermal aging for longer times and at several higher temperatures. More couples with metal contacts are being fabricated and will be life tested isothermally and in gradient operation to obtain power as a function of time.

The room temperature resistance of this couple is very close $(<5 \%)$ as compared to the calculated values of the $\mathrm{N} \& \mathrm{P}$ materials as shown in Table 1. The voltage output (at ) T 5/C) of the couple near room temperature, also shown in Table 1, is also in agreement with the expected values.

Table 1. Thermoelectric properties of QW couple with Mo contact compared to calculated values.

\begin{tabular}{|l|c|c|}
\hline Room temperature properties & Measured & Calculated \\
\hline Couple Resistance & $1.23 \mathrm{kS}$ & $1.25 \mathrm{kS}$ \\
\hline Couple Voltage Output @ ) T $5 / \mathrm{C}$ & $4.56 \mathrm{mV}$ & $4.60 \mathrm{mV}$ \\
\hline
\end{tabular}

The significance of these couples with Mo contacts is that the Hi-Z developed and improved sputtering process was able to make good electric contact with all of the 1,100 QW layers in the 11 $\mu \mathrm{m}$ thick film (each layer is $100 \mathrm{D}$ thick). It has been difficult to achieve this low contact resistance on some specimens in the past. Failure to contact each layer will typically lead to very high and/or erroneous resistivities [8].

Based on prior Sandia studies with SiGe alloys, we expect Mo or W contacts to be stable at $\$ 450^{\circ} \mathrm{C}$ [8]. At a $\mathrm{T}_{\mathrm{H}}$ of $500^{\circ} \mathrm{C}$ and $\mathrm{T}_{\mathrm{C}}$ of $50^{\circ} \mathrm{C}$, the calculated efficiency for a N-type $\mathrm{Si} / \mathrm{SiGe}$ and P-type $\mathrm{B}_{4} \mathrm{C} / \mathrm{B}_{9} \mathrm{C}$ module is $\sim 18 \%$. When the $\mathrm{Si} / \mathrm{SiC} \mathrm{QW}$ are qualified with thicker films, we expect an efficiency of $\sim 21 \%$ at these same temperatures.

For higher temperatures (up to 1000/C), Hi-Z plans to use the Si-Mo alloys as the contacting materials, which are the same materials used as the hot shoes in the SiGe multi hundred Watt generators. Hi-Z will also deposit these alloys by the improved sputtering process. 


\section{Thermal aging QW couple resistance ratio}

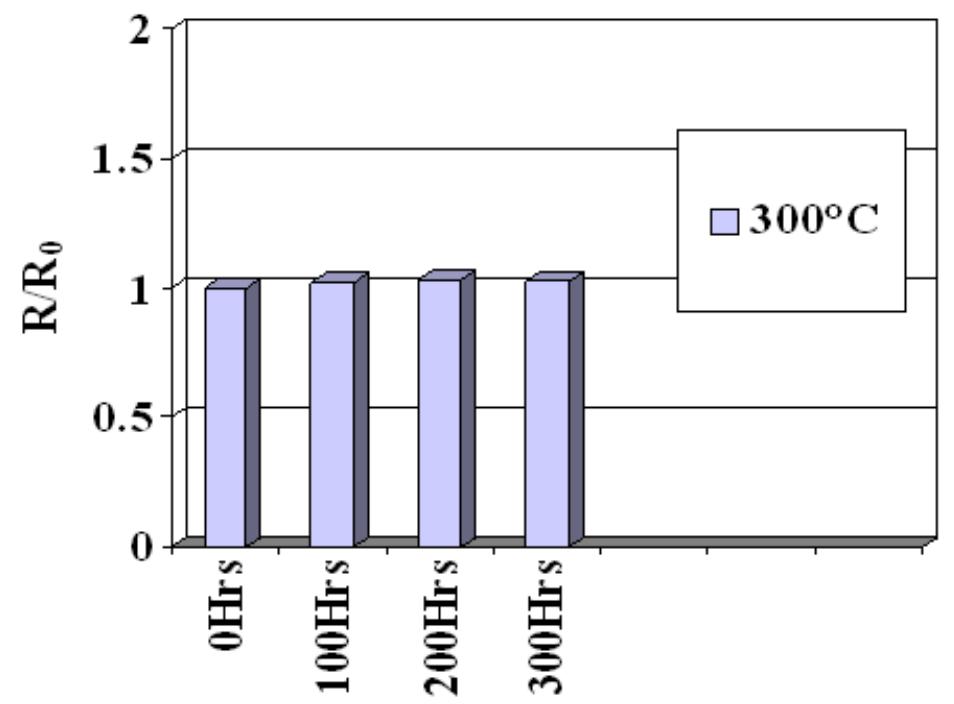

Figure 9. Isothermal aging studies of $\mathrm{Si} / \mathrm{SiGe}-\mathrm{B}_{4} \mathrm{C} / \mathrm{B}_{9} \mathrm{C}$ couple.

$\mathrm{Y}$-axis is the resistivity ratio at various aging time. The resistance ratio includes both the resistance of the QW Si/SiGe plus $\mathrm{B}_{4} \mathrm{C} / \mathrm{B}_{9} \mathrm{C}$ samples as well as the Mo metal used to make the low resistance contact. Individual aging of the contact and the QW films are shown in the following figures.

\section{Thermal aging contact resistance ratio}

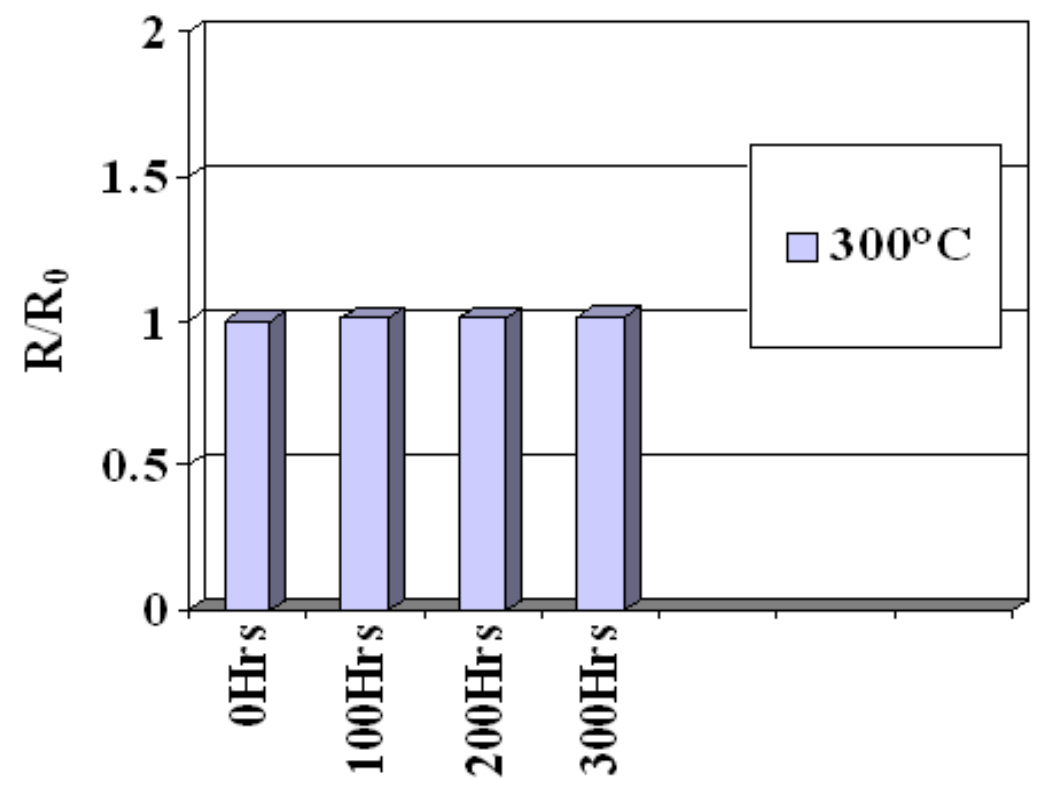

Figure 10. Thermal aging of sputtered Mo contact. 


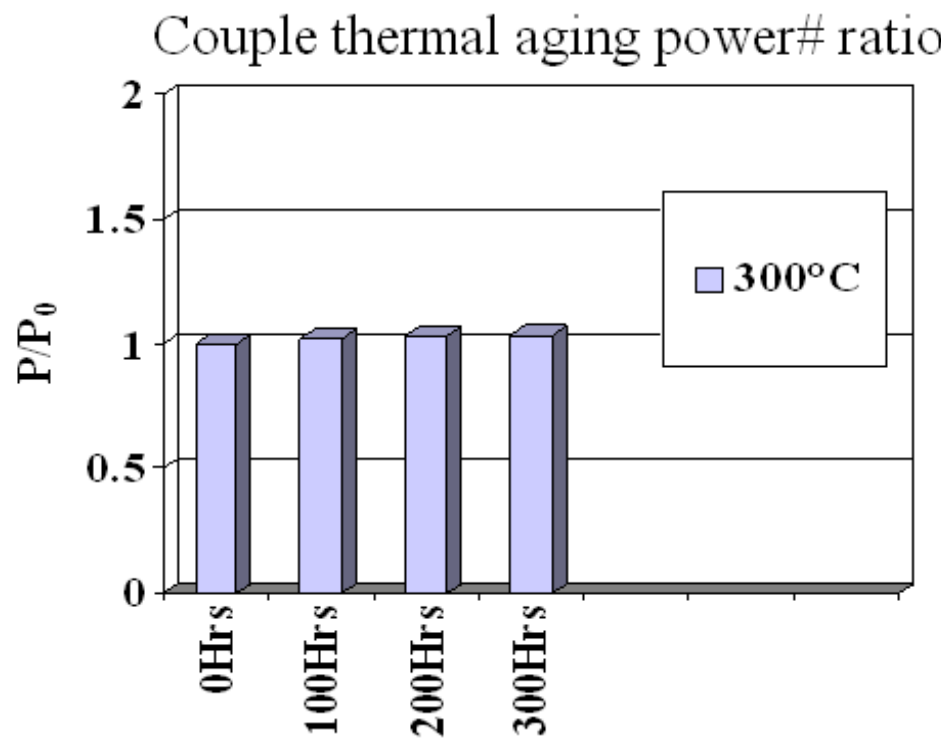

Figure 11. Thermal aging of QW couple with Mo contact power number $=" 2 / D$

\section{Hi-Z Samples Comparison}

Pacific Northwest National Laboratory (PNNL) with funding from the DOE has fabricated and measured and $\mathrm{B}_{4} \mathrm{C} / \mathrm{B}_{9} \mathrm{C}$ and $\mathrm{Si} / \mathrm{SiGe}$ samples. These samples were fabricated in the same way as the Hi-Z samples. The measured resistivity and Seebeck coefficient (done at PNNL) shows similar values as the Hi-Z samples. PNNL results are shown in Figure 12.

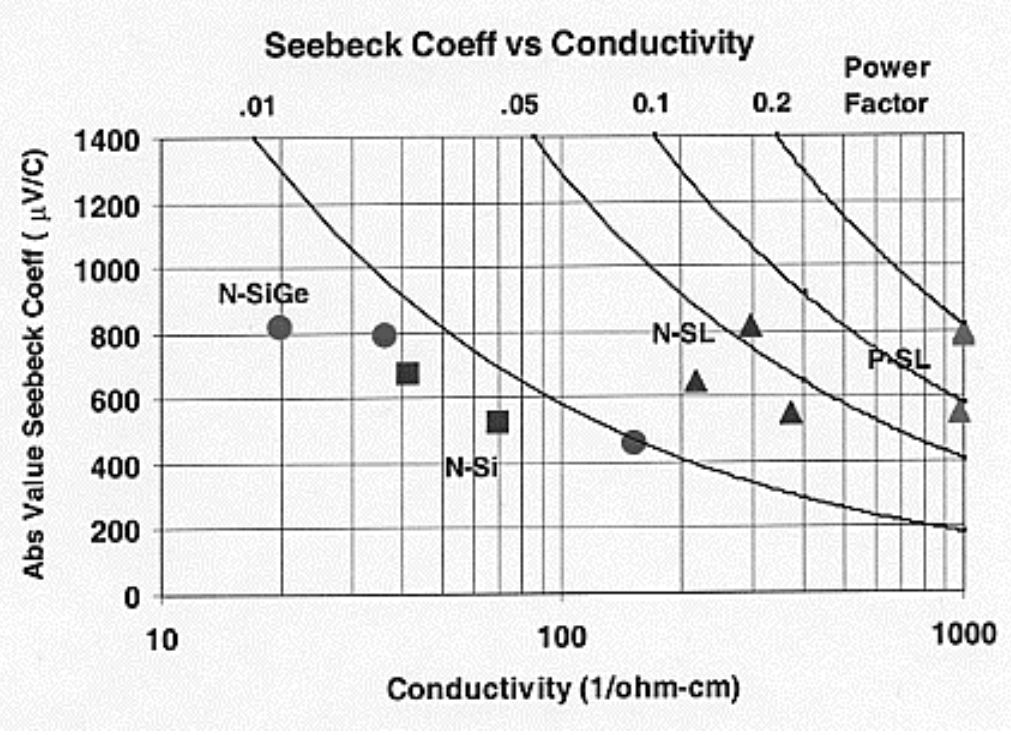

Figure 12. PNNL experimental results 
Samples fabricated by Hi-Z were also measured by NRL, the results are shown in Figure 13. The results are also similar to the Hi-Z's and PNNL's results. Table 2 summarizes these comparisons.

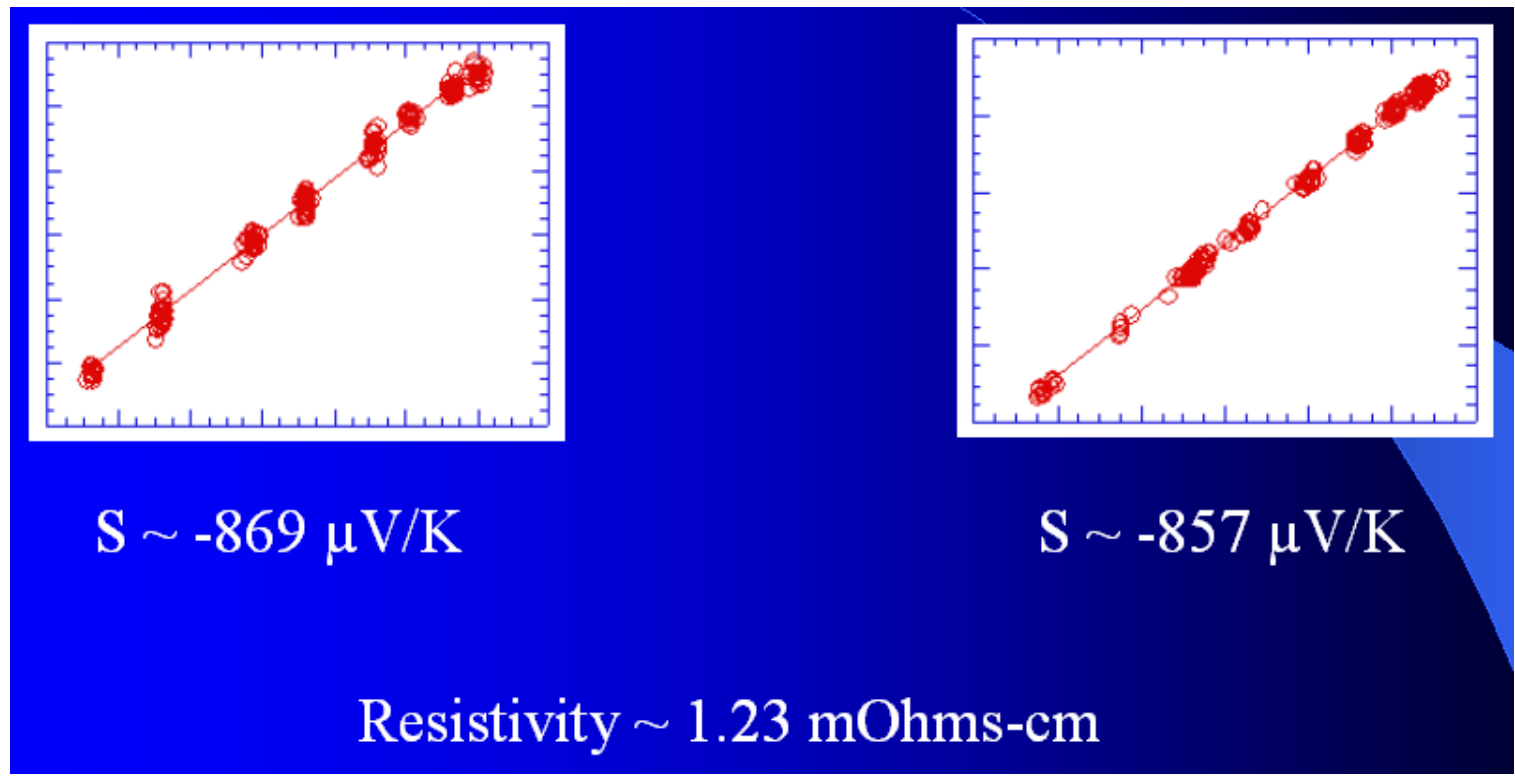

Figure 13. NRL Thermopower measurement of Hi-Z Si/SiGe Film on Silicon.

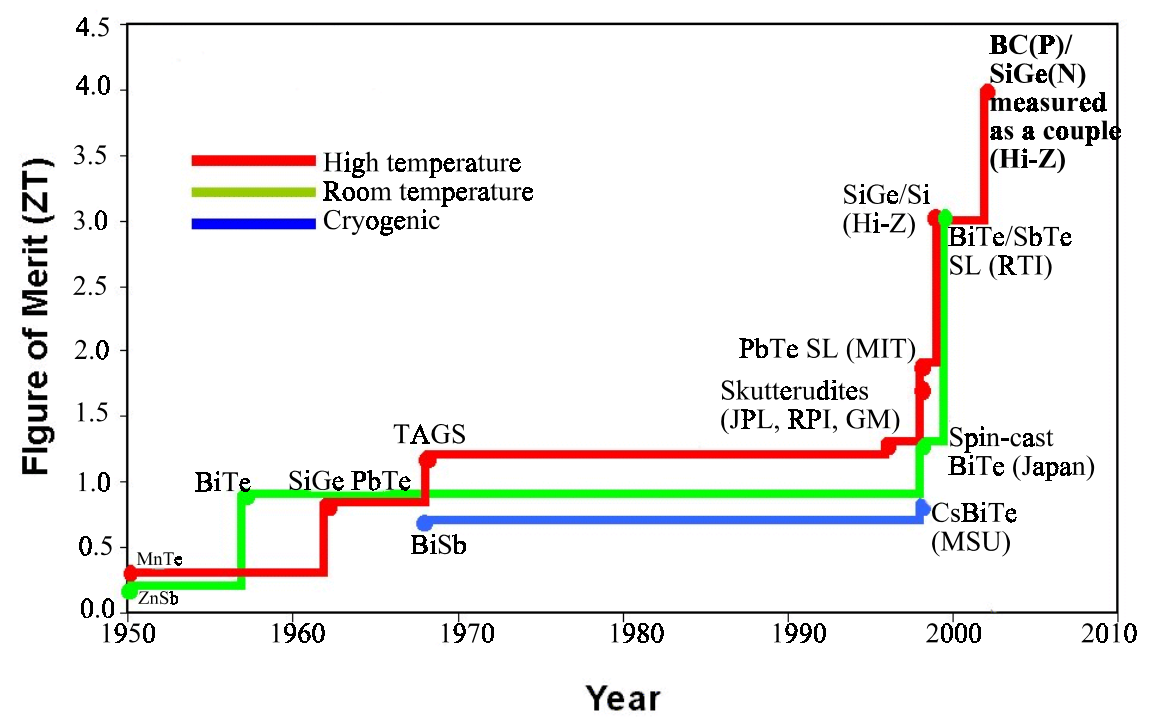

Figure 14. ZT Time Line 
Table 2. TE Properties Comparison. The room temperature Resistivity ( $\rho$ )and Seebeck $(\alpha)$ were measured at the noted institutes but the thermal conductivity and high temperature $\alpha$ and $\rho$ were only measured at $\mathrm{Hi}-\mathrm{Z}$.

\begin{tabular}{|c|c|c|c|c|c|c|}
\hline $\begin{array}{c}\text { Sample } \\
\text { Composition }\end{array}$ & $\begin{array}{l}\text { Sample } \\
\text { ID }\end{array}$ & $\begin{array}{c}\text { Fabricated } \\
\text { @ }\end{array}$ & $\begin{array}{c}\text { Measured } \\
\text { a }\end{array}$ & $\begin{array}{l}\alpha^{2} / \rho @ 25 / \mathrm{C} \\
\left(\mu \mathrm{W} / \mathrm{cm}-\mathrm{K}^{2}\right)\end{array}$ & $\begin{array}{l}\text { ZT@ } \\
25 / \mathrm{C}\end{array}$ & $\begin{array}{l}\mathrm{ZT} @ \\
150 / \mathrm{C}\end{array}$ \\
\hline \multirow{4}{*}{ Si/SiGe } & HZ062 & $\mathrm{Hi}-\mathrm{Z}$ & $\mathrm{Hi}-\mathrm{Z}$ & 710 & 2.1 & 3.0 \\
\hline & HZ062 & $\mathrm{Hi}-\mathrm{Z}$ & NRL & 605 & 1.8 & - \\
\hline & $2 \mathrm{BK}-\mathrm{S}$ & PNNL & PNNL & 690 & 2.0 & - \\
\hline & 2BK-S & PNNL & $\mathrm{Hi}-\mathrm{Z}$ & 686 & 2.0 & 2.6 \\
\hline \multirow{4}{*}{$\mathrm{B}_{4} \mathrm{C} / \mathrm{B}_{9} \mathrm{C}$} & HZ102 & $\mathrm{Hi}-\mathrm{Z}$ & $\mathrm{Hi}-\mathrm{Z}$ & 920 & 2.9 & 4.1 \\
\hline & HZ102 & $\mathrm{Hi}-\mathrm{Z}$ & NRL & 891 & 2.8 & - \\
\hline & $1 \mathrm{~W}-\mathrm{PB}$ & PNNL & $\mathrm{Hi}-\mathrm{Z}$ & 860 & 2.7 & 3.8 \\
\hline & $1 \mathrm{~W}-\mathrm{PB}$ & PNNL & PNNL & 822 & 2.6 & - \\
\hline $\mathrm{Bi}_{2} \mathrm{Te}_{3}$ alloy & - & - & Published & $\sim 80$ & $\sim 1$ & $\sim 1$ \\
\hline
\end{tabular}

As shown in Table 2, the $\mathrm{Bi}_{2} \mathrm{Te}_{3}$ alloys has a value of $\mathrm{ZT}$ of about 1 . As shown in Figure 14, the value of ZT has hovered around 1 since the mid-1950s when semi-conductor materials were introduced into thermoelectric conversion. In the late 1990s new materials, including quantum well materials, started to increase the value of ZT to a out 4 (Table 2) with some promise that even higher values can be obtained as development continues.

\section{The Sputtering Machine}

The purchase of the 34" sputtering machine was completed The system was delivered and installed in February 2005. The system shown in Figure 15, was checked out by the PI. The final payment of $\$ 32,230$ will be made upon operational checkout of the new sputtering machine in Hi-Z's facilities in March 2005. DOE ORO's payment of the agreed $\$ 100,000$ share of the $\$ 322,300$ total cost of the machine was received in the first week of January. NETL's agreed share of $\$ 105,000$ was received January $16^{\text {th }}$. NASA's agreed share of $\$ 90,000$ was received April 8, 2004 NAVSEA's share amounting to $\$ 27,300$ will be billed to them in advance of the operational checkout and the final payment. The government funds awaiting the next disbursement to the fabricator are being held in a special interest-bearing money market account restricted to government funds. 


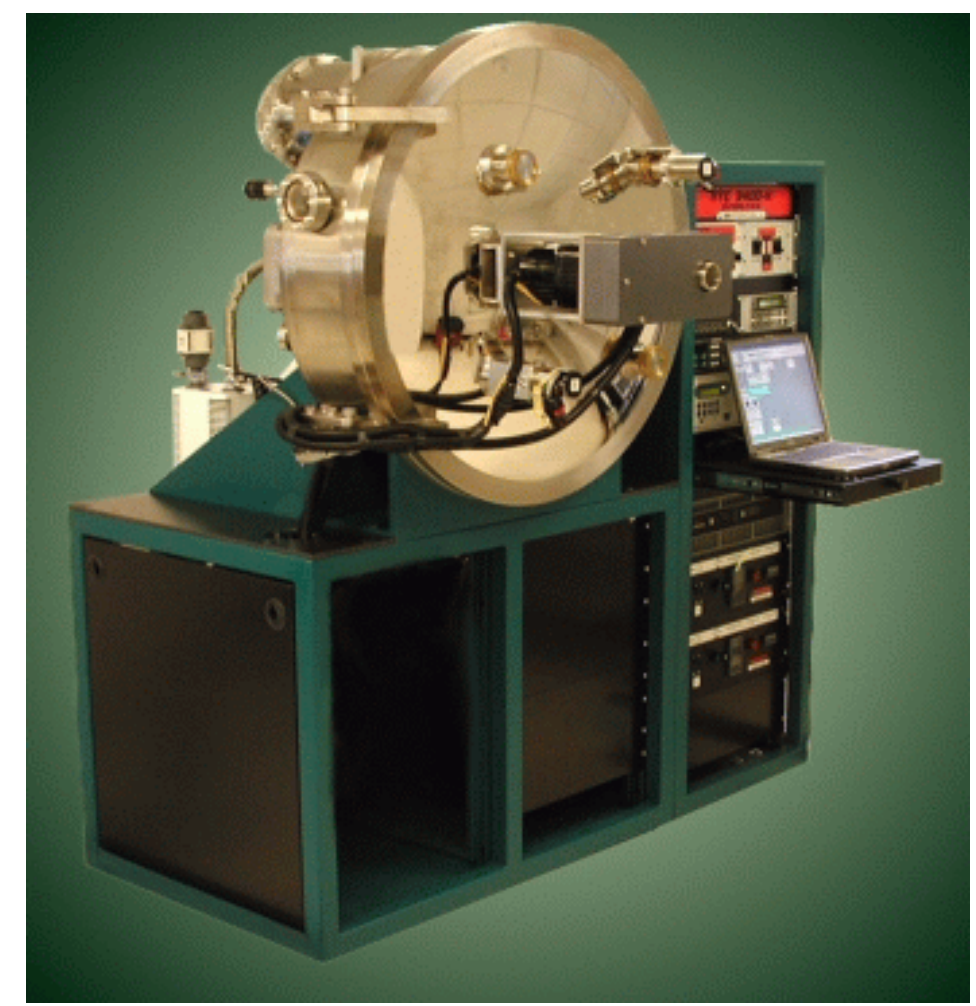

Figure 15. Hi-Z new sputtering 34" diameter chamber processes up to (6) 8 " wafers, (9) 6" wafers or hundreds of small substrates with up to 4 different materials. The system shown is fitted with 400/C backside quartz lamp heating, mag-lev turbo and a dry pump.

\section{REFERENCES/BIBLIOGRAPHYIACRONYMS}

Any references and bibliography are as submitted in the proposal, pages 24 and 25. Acronyms and abbreviations are explained the first time they appear in the text. 